\title{
ANALISIS KONSENTRASI KARBON MONOKSIDA (CO) DAN SULFUR DIOKSIDA (SO2) UDARA PADA SUMBER BERGERAK DI JALAN A.P PETTARANI DAN RAPOCCINI RAYA KOTA MAKASSAR \\ Analysis Of Concentration Of Carbon Monoxide (Co) And Sulfur Dioxide (So2) Air In Moving Sources In Jalan A.P Pettarani And Rapoccini Raya Kota Makassar \\ Andi Ruhban ${ }^{1}$ dan Indah Rahmadana ${ }^{2}$ \\ 1,2 Jurusan Kesehatan Lingkungan Poltekkes Kemenkes Makassar Indahrahmadana.Ir@gmail.com
}

\begin{abstract}
Carbon monoxide is a colorless gas, odorless and tasteless. Sulfur dioxide is one species of sulfur oxide gases (SO2). This gas is very easily dissolved in water, has a smell but is colorless. The purpose of this research is to know the concentration of Carbon Monoxide and Sulfur Dioxide in the air at the source of moving on the road $A$. P. Pettarani and Rapoccini Raya Makassar city. This type of research is descriptive research by doing the measurement directly in the field. The results of the CO study were obtained on A.P. Pettarani (crossroads Urip Sumoharjo in the morning and afternoon is 5,725 ug / m3 and $18580 \mathrm{ug} / \mathrm{m} 3$ ) and (crossroads Sultan Alauddin in the morning and afternoon is 5,325 ug / $\mathrm{m3}$ and $11623 \mathrm{ug} / \mathrm{m3}$ ) while the results obtained in the road Rapoccini Kingdom (Crossroads South Veterans on the morning and afternoon is 6,184 ug / m3 and 5,640 ug / m3) and (crossroads APPettarani in the morning and afternoon is $6527 \mathrm{ug} / \mathrm{m3}$ and 5,239 ug / m3). The results showed that the highest concentration of Carbon Monoxide was found in A.P. Pettarani Urip Sumoharjo crossroads in the afternoon. Results Monoxide (CO) in the morning and afternoon on A.P. Pettarani and road Rapoccini Raya Makassar, the highest yield in the afternoon streets A.P. Pettarani (crossroads urip Sumoharjo) amounted to $18580 \mathrm{mg} / \mathrm{Nm3}$, whereas the lowest yield in the afternoon streets Rapoccini Kingdom (crossroads Pettarani) of 5,239 mg / Nm3. still meets the conditions set by South Sulawesi Governor Regulation Number 69 of 2010 Concerning Air Quality Standards and Criteria for Environmental Damage, for Carbon Monoxide to the standard 30,000 mg / Nm3.
\end{abstract}

Keywords: Carbon Monoxide and Sulfur Dioxide

\section{ABSTRAK}

Karbon monoksida adalah gas yang tak berwarna, tidak berbau dan juga tidak berasa. Sulfur dioksida adalah salah satu spesies dari gas-gas oksida sulfur (SO2). Gas ini sangat mudah terlarut dalam air, memiliki bau namun tidak berwarna. Tujuan dari penelitian ini adalah Mengatahui Konsentrasi Karbon Monoksida dan Sulfur Dioksida di udara pada sumber bergerak di jalan A. P. Pettarani dan Rapoccini Raya kota Makassar. Jenis penelitian ini merupakan penelitian deskriftif dengan melakukan pengukuran secara langsung di lapangan. Hasil penelitian $\mathrm{CO}$ diperoleh di jalan A.P. Pettarani (Persimpangan jalan Urip Sumoharjo pada pagi dan sore yaitu $5.725 \mu \mathrm{g} / \mathrm{m}^{3}$ dan $18.580 \mu \mathrm{g} / \mathrm{m}^{3}$ ) dan (Persimpangan jalan Sultan Alauddin pada pagi dan sore yaitu $5.325 \mu \mathrm{g} / \mathrm{m}^{3}$ dan $11.623 \mu \mathrm{g} / \mathrm{m}^{3}$ ) sedangkan hasil yang diperoleh di jalan Rapoccini Raya (Persimpangan jalan Veteran Selatan pada pagi dan sore yaitu $6.184 \mu \mathrm{g} / \mathrm{m}^{3}$ dan $5.640 \mu \mathrm{g} / \mathrm{m}^{3}$ ) dan (Persimpangan jalan A.P.Pettarani pada pagi dan sore yaitu $6.527 \mu \mathrm{g} / \mathrm{m}^{3}$ dan $5.239 \mu \mathrm{g} / \mathrm{m}^{3}$ ). Dari hasil penelitian menunjukkan bahwa konsentrasi Karbon Monoksida tertinggi terdapat pada jalan A.P. Pettarani Persimpangan jalan Urip Sumoharjo pada sore. Hasil penelitian SO2 disemua lokasi diperoleh nihil (memenuhi syarat). Konsentrasi Karbon Monoksida (CO) pada pagi dan sore hari dijalan A.P. Pettarani dan jalan Rapoccini Raya Kota Makassar, hasil tertinggi pada sore hari dijalan A.P. Pettarani (persimpangan jalan urip sumoharjo) sebesar 18.580 $\mu \mathrm{g} / \mathrm{Nm} 3$, sedangkan hasil terendah pada sore hari dijalan Rapoccini Raya (persimpangan jalan pettarani) sebesar 5.239 $\mu \mathrm{g} / \mathrm{Nm} 3$. masih memenuhi syarat yang ditetapkan oleh Peraturan Gubernur Sulawesi Selatan Nomer 69 Tahun 2010 Tentang Baku Mutu Udara Dan Kriteria Kerusakan Lingkungan Hidup, untuk Karbon Monoksida dengan standar 30.000 $\mu \mathrm{g} / \mathrm{Nm} 3$.

Kata kunci : Karbon Monoksida dan Sulfur Dioksida

\section{PENDAHULUAN}

Pada dasarnya penyebab polusi udara serupa dengan polusi air. Pencemaran udara ialah jika udara di atmosfer di campur dengan zat atau radiasi yang berpengaruh jelek terhadap organisme hidup. Pencemaran udara erat kaitannya dengan segala aktivitas manusia, dimana manusia senantiasa mengolah kekayaan alam yang ada tanpa memperhatikan dampak yang disubsidi terhadap lingkungan. (Sastrawijaya, 1991).

Di samping itu pencemaran udara di pengaruhi oleh pembangunan yang berkembang pesat dewasa ini, khususnya dalam bidang industri dan teknologi serta meningkatkan jumlah kendaraan bermotor yang menggunakan kendaraan bermotor dan yang menggunakan bahan bakar fosil (minyak) menyebabkan udara yang kita hirup disekitar menjadi tercemar oleh gabungan hasil pembakaran. (Wardhana, 2001).

Sumber utama pencemaran Karbon Monoksida (CO) dan Sulfur Dioksida $\left(\mathrm{SO}_{2}\right)$ berasal dari kendaraan bermotor. Di Amerika pada tahun 1969 diperkirakan sebagian besar kendaraan bermotor yang menghasilkan 97 ribu ton gas Karbon Monoksida (CO) yang merupakan $65 \%$ dari seluruh Karbon Monoksida (CO) buatan manusia. Dengan demikian maka $60 \%$ gas Karbon Monoksida (CO) ditemukan di kota-kota besar dan wilayah perkotaan. (Mukono, 1997). 
Dalam beberapa penelitian ditemukan kadar Karbon Monoksida (CO) yang cukup tinggi didalam kendaraan sedan maupun bus. Kadar Karbon Monoksida (CO) diperkotaan cukup bervariasi tergantung dari kepadatan kendaraan bermotor yang menggunakan bahan bakar bensin dan umumnya ditemukan kadar maksimum $\mathrm{CO}$ yang bersamaan dengan jam-jam sibuk pada pagi dan malam hari. Selain cuaca, variasi dari kadar CO juga dipengaruhi oleh topografi jalan dan bangunan disekitarnya. (Yuli Cs, 2007).

\section{METODE}

Lokasi penelitian adalah dipilih dengan 2 lokasi yaitu dijalan A.P. Pettarani dan jalan Rapoccini Raya, dengan mengambil 4 titik dan dua kali pengukuran.

\section{Pengumpulan Data}

a. Data Primer

Data Primer dalam penelitian ini adalah data penelitian yang diperoleh dari hasil pengukuran kadar karbon monoksida (CO) dan data yang diperoleh dari hasil pengamatan langsung dijalan raya

b. Data Sekunder

Data sekunder dalam penelitian ini adalah data yang diperoleh dari hasil studi kepustakaan serta literatur-literatur yang ada hubungannya dengan objek penelitian, data dari SAMSAT (Jumlah kendaraan di kota Makassar) serta dari situs internet.

\section{Pengolahan dan analisis data}

Data hasil pengukuran Karbon Dioksida dan Sulfur Dioksida diudara akan diolah dengan melakukan pengukuran di lapangan. Data tersebut disajikan dalam bentuk tabel dan dinarasikan kemudian hasil pemeriksaan dianalisa secara deskriptik.

\section{HASIL}

1. Hasil Pengukuran Konsentrasi Karbon Monoksida pada tanggal 18 - 19 Mei 2017 pagi dan sore hari di jalan A.P. Pettarani dan Rapoccini Raya Kota Makassar.

\section{Tabel 1}

Hasil Pengukuran Konsentrasi Karbon Monoksida Tanggal 18 - 19 Mei 2017 Pagi dan Sore Hari Di Jalan A.P. Pettarani Dan Rapoccini Raya Kota Makassar

\begin{tabular}{|c|c|c|c|c|}
\hline $\begin{array}{l}\mathbf{N} \\
\mathbf{O}\end{array}$ & $\begin{array}{c}\text { Titik } \\
\text { Pengukura } \\
\mathbf{n}\end{array}$ & $\begin{array}{c}\text { Waktu } \\
\text { Pengukur } \\
\text { an }\end{array}$ & $\begin{array}{c}\text { Hasil } \\
\text { CO } \\
\text { (ppm } \\
\text { ) }\end{array}$ & $\begin{array}{c}\text { Hasil } \\
\text { CO } \\
\mu \mathrm{g} / \mathrm{Nm} \\
3 \\
\end{array}$ \\
\hline 1 & $\begin{array}{l}\text { Persimpang } \\
\text { an jalan Urip } \\
\text { Sumoharjo } \\
\text { dan A.P. } \\
\text { Pettarani }\end{array}$ & $\begin{array}{l}07: 00- \\
08: 00\end{array}$ & 5 & 5.725 \\
\hline 2 & $\begin{array}{l}\text { Persimpang } \\
\text { an jalan } \\
\text { Sultan } \\
\text { Alauddin } \\
\text { dan A.P. } \\
\text { Pettarani }\end{array}$ & $\begin{array}{c}09: 00- \\
10: 00\end{array}$ & 4,65 & 5.325 \\
\hline 3 & $\begin{array}{l}\text { Persimpang } \\
\text { an jalan Urip } \\
\text { Sumoharjo } \\
\text { dan A.P. } \\
\text { Pettarani }\end{array}$ & $\begin{array}{c}15: 00- \\
16: 00\end{array}$ & $\begin{array}{c}16,22 \\
5\end{array}$ & 18.58 \\
\hline
\end{tabular}

Persimpang

an jalan

$4 \begin{array}{llll}\text { Sultan } & 17: 00- & 10,15 & 11.62\end{array}$

dan A.P.

Pettarani

\begin{tabular}{|c|c|c|c|c|}
\hline 5 & $\begin{array}{l}\text { Persimpang } \\
\text { an jalan } \\
\text { Veteran } \\
\text { Selatan dan } \\
\text { Rapoccini }\end{array}$ & $\begin{array}{l}\text { 07:00- } \\
\text { 08:00 }\end{array}$ & 5,4 & 6.184 \\
\hline 6 & $\begin{array}{l}\text { Persimpang } \\
\text { an jalan A.P. } \\
\text { Pettarani } \\
\text { dan } \\
\text { Rapoccini }\end{array}$ & $\begin{array}{c}09: 00- \\
10: 00\end{array}$ & 5,7 & 6.527 \\
\hline
\end{tabular}

\begin{tabular}{|c|c|c|c|c|}
\hline 7 & $\begin{array}{l}\text { Persimpang } \\
\text { an jalan } \\
\text { Veteran } \\
\text { Selatan dan } \\
\text { Rapoccini }\end{array}$ & $\begin{array}{c}15: 00- \\
16: 00\end{array}$ & 4,925 & 5.64 \\
\hline 8 & $\begin{array}{l}\text { Persimpang } \\
\text { an jalan A.P. } \\
\text { Pettarani } \\
\text { dan } \\
\text { Rapoccini }\end{array}$ & $\begin{array}{c}17: 00- \\
18: 00\end{array}$ & 4,575 & 5.239 \\
\hline
\end{tabular}

Sumber: Data Primer, 2017 Keterangan

:Standar baku mutu udara untuk karbon

monoksida yaitu $30.000 \mu \mathrm{g} / \mathrm{Nm} 3$. (Peraturan

Gubernur Sul-Sel Nomor 69 Tahun 2010)

2. Hasil Pengukuran Konsentrasi Sulfur Dioksida pada tanggal 18 - 19 Mei 2017 pagi dan sore hari di jalan A.P. Pettarani dan Rapoccini Raya Kota Makassar.

\section{Tabel 2}




\begin{tabular}{ccccc}
\hline \hline \multicolumn{3}{c}{ Hasil Pengukuran Konsentrasi Sulfur } \\
Dioksida Tanggal 18 - 19 Mei 2017 Pagi \\
dan Sore Hari Di Jalan A.P. Pettarani dan \\
Rapoccini Raya Kota Makassar
\end{tabular}

3. Hasil Pengukuran Suhu, Kelembaban, dan Kecepatan Angin Dari BMKG (Badan Metereologi Klimatologi dan Geofisika)

Tabel 3

\begin{tabular}{cccc}
\hline $\begin{array}{c}\text { Hari/Tangga } \\
\text { I }\end{array}$ & $\begin{array}{c}\text { Suh } \\
\mathbf{u}\end{array}$ & $\begin{array}{c}\text { Kelembaba } \\
\mathbf{n}\end{array}$ & $\begin{array}{c}\text { Kecepata } \\
\mathbf{n} \text { angin }\end{array}$ \\
\hline $\begin{array}{c}\text { Kamis, 18 } \\
\text { Mei 2017 }\end{array}$ & $30^{\circ} \mathrm{C}$ & $45 \%$ & $\begin{array}{c}4,10 \\
\mathrm{~m} / \text { detik }\end{array}$ \\
\hline $\begin{array}{c}\text { Jumat, 19 } \\
\text { Mei 2017 }\end{array}$ & $40^{\circ} \mathrm{C}$ & $30 \%$ & $\begin{array}{c}4,30 \\
\text { m/detik }\end{array}$ \\
\hline
\end{tabular}

Sumber: Data Skunder, 2017
1. Hasil Pengukuran Kadar Karbon Monoksida Di Jalan A.P. Pettarani Dan Rapoccini Raya Kota Makassar Pada Tanggal 18 - 19 Mei 2017.

Berdasarkan tabel 1 pengukuran kadar Karbon Monoksida diketahui bahwa dari 2 lokasi 8 titik pengukuran yang dilakukan dijalan A.P. Pettarani dan jalan Rapoccini Raya Kota Makassar, pada pengukuran Karbon Monoksida tanggal 18 Mei 2017 pagi hari dilakukan di titik I (persimpangan jalan Urip Sumoharjo dan Pettarani) dengan hasil pengukuran 5.725 $\mu \mathrm{g} / \mathrm{Nm} 3$, titik II (persimpangan jalan Sultan Alauddin dan Pettarani) dengan hasil pengukuran $5.325 \mu \mathrm{g} / \mathrm{Nm} 3$,

dan untuk pengukuran sore hari dilakukan di titik III (persimpangan jalan Urip Sumoharjo dan Pettarani) dengan hasil pengukuran $18.580 \mu \mathrm{g} / \mathrm{Nm} 3$, titik IV (persimpangan jalan Sultan Alauddin dan Pettarani) dengan pengukuran 11.623 $\mu \mathrm{g} / \mathrm{Nm} 3$

Sedangkan pada tanggal 19 mei 2017 pagi hari dilakukan di titik I (persimpangan jalan Veteran Selatan dan Rapoccini) dengan pengukuran 6.184 $\mu \mathrm{g} / \mathrm{Nm} 3$,, titik II (persimpangan jalan Pettarani dan Rapoccini) dengan pengukuran $6.527 \mu \mathrm{g} / \mathrm{Nm} 3$, dan untuk pengukuran sore hari dilakukan dititik III (persimpangan jalan Veteran Selatan dan Rapoccini) dengan pengukuran 5.640 $\mu \mathrm{g} / \mathrm{Nm} 3$, dan titik IV (persimpangan jalan Sultan Alauddin dan Pettarani) dengan pengukuran $5.239 \mu \mathrm{g} / \mathrm{Nm} 3$.

Adapun hasil penelitian tertinggi pada saat pengukuran pada tanggal 18 mei 2017 pada pengukuran sore hari di titik III (persimpangan jalan Urip Sumoharjo dan Pettarani) dengan hasil pengukuran $18.580 \mu \mathrm{g} / \mathrm{Nm} 3$.

Hasil pengukuran suhu dan kelembaban pada tanggal 18 mei 2017, suhu $30{ }^{\circ} \mathrm{C}$, kelembaban $45 \%$, kecepatan sedangkan untuk tanggaal 19 mei, suhu $40^{\circ} \mathrm{C}$, kelembaban $30 \%$.

Secara teoritas di jelaskan bahwa jika suhu meningkat akan meningkat pula reaksi suatu bahan kimia begitupun sebaliknya dan semakin renda kelembaban udara di daerah tercemar akan mengurangi efek korosif dari bahan kimia tersebut. Namun kenyataannya dari hasil pengukuran pada tanggal 18 mei 2017 dijalan persimpangan Urip Sumoharjo dan AP. Pettarani suhu udara menurun sedangkan hasil konsentrasi 
Karbon Monoksida tinggi dibandingkan dengan pada tanggal 19 mei 2017 dijalan persimpangan A.P. Pettarani dan Rapoccini Raya hasil yang diperoleh sangan rendah sedangkan suhu udara sangat tinggi. Hal ini disebabkan karena adanya tingkat kepadatan kendaraan pada saat dilakukan pengukuran di jalan persimpangan Urip Sumoharjo dan A.P Pettarani, selain itu juga terdapat banyak bangunan disekitar persimpangan jalan Urip Sumoharjo dan A.P. Pettarani kemungkinan besar menghasilkan gas karbon monoksida karena kita ketahui bahwa konsentrasi Karbon Monoksida tidak hanya dipengaruhi oleh suhu kelembaban saja hanya saja dipengaruhi oleh adanya aktivitas-aktivitas tertentu yang mengharuskan manusia berpergian dengan menggunakan sumber bergerak (kendaraan), sehingga terjadi kepadatan lalu lintas dimana apabila adanya kemacetan di jalan tersebut maka akan terjadi proses pembakaran tidak sempurna pada setiap kendaraan dan akan menghasilkan karbon monoksida.

Adapun hal lain yang dapat mempengaruhi hasil konsentrasi karbon monoksida yaitu kecepatan angin dimana semakin cepat kecepatan angin semakin menurun konsentrasi karbon monoksida begitupun sebalinya jika kecepatan angin rendah maka semakin tinggi konsentrasi karbon monoksida, sedangkan pada tanggal 18 mei 2017 dijalan persimpangan Urip Sumoharjo dan A.P. Pettarani kecepatan angin rendah yaitu $4,10 \mathrm{~m} /$ detik dibandingkan dengan pada tanggal 19 mei 2017 jalan A.P. Pettarani dan Rapoccini Raya yaitu $4,30 \mathrm{~m} /$ detik.

Dari 8 titik hasil pengukuran tersebut, konsentrasi Karbon Monoksida dijalan A.P. Pettarani dan Rapoccini Raya Kota Makassar masih memenuhi syarat ketetapan Peraturan Gubernur Sul-Sel Nomor 69 Tahun 2010 Tentang Baku Mutu Dan Kriteria Kerusakan Lingkungan Hidup, akan tetapi hal ini perlu ditindak lanjuti sebagai salah satu langkah pencegahan dan meminimalkan terjadinya dampak yang ditimbulkan.

Sumber gas CO sebagian besar berasal dari pembakaran bahan bakar fosil yang bereaksi dengan udara menghasilkan gas buangan, salah satunya adalah karbon monoksida. Daerah dengan tigkat populasi yang tinggi dengan jalur lalu lintas yang padat akan memiliki kadar $\mathrm{CO}$ yang lebih tinggi dibandingkan dengan daerah pedesaan. Sumber $\mathrm{CO}$ buatan antara lain kendaraan bermotor, terutama yang menggunakan bahan bakar bensin. (Zulfa, 2011).

2. Hasil Pengukuran Kadar Sulfur Dioksida Di Jalan A.P. Pettarani Dan Rapoccini Raya Kota Makassar

Berdasarkan tabel 2 pengukuran kadar sulfur dioksida diketahui bahwa dari 2 lokasi dan 8 titik pengukuran yang di lakukan dijalan A.P. Pettarani dan jalan Rapoccini Raya Kota Makassar pada pengukuran Sulfur Dioksida (SO2) tanggal 18-19 mei 2017 pengukuran di pagi dan sore hari diketahui hasil SO2 nya (Nihil), berarti masih memenuhi syarat ketetapan Peraturan Gubernur Sul-Sel Nomor 69 Tahun 2010 Tentang Baku Mutu Dan Kriteria Kerusakan Lingkungan Hidup, akan tetapi hal ini perlu ditindak lanjuti sebagai salah satu langkah pencegahan dan meminimalkan terjadinya dampak yang ditimbulkan.

Hasil pengukuran suhu dan kelembaban pada tanggal 18 mei 2017, suhu $30{ }^{\circ} \mathrm{C}$, kelembaban $45 \%$, kecepatan sedangkan untuk tanggaal 19 mei, suhu $40^{\circ} \mathrm{C}$, kelembaban $30 \%$.

Secara teoritas di jelaskan bahwa jika suhu meningkat akan meningkat pula reaksi suatu bahan kimia begitupun sebaliknya dan semakin rendah kelembaban udara di daerah tercemar akan mengurangi efek korosif dari bahan kimia tersebut. Namun kenyataannya dari hasil pengukuran pada tanggal 18 mei 2017 dijalan A.P. Pettarani dan Rapoccini Raya suhu udara menurun sedangkan hasil konsentrasi Sulfur Dioksida sama sekali tidak ditemukan sama pada tanggal 19 mei 2017 dijalan A.P. Pettarani dan Rapoccini Raya hasil yang diperoleh (Nihil) sedangkan suhu udara sangat tinggi.

Adapun hal lain yang dapat mempengaruhi hasil konsentrasi Sulfur Dioksida yaitu kecepatan angin dimana semakin cepat kecepatan angin semakin menurun gas Sulfur Dioksida begitupun sebalinya jika kecepatan angin rendah maka semakin tinggi konsentrasi gas sulfur dioksida, sedangkan pada tanggal 18 mei 2017 dijalan A.P. Pettarani dan Rapoccini Raya kecepatan angin rendah yaitu 4,10 $\mathrm{m} /$ detik dibandingkan dengan pada tanggal 19 mei 2017 dijalan A.P. Pettarani dan Rapoccini Raya yaitu 4,30 m/detik. 


\begin{abstract}
Secara teoritis dijelaskan bahwa sumber utama pencemaran gas sulfur dioksida (SO2) yaitu adanya prosesproses alami seperti aktivitas vulkanik, pembusukan sampah tanaman, kebakaran hutan dan sebagainya, yang tersebar oleh angin di udara. Sebagian besar sumber penecemaran di udara berasal dari aktivitas industri yaitu pembakaran batu arang. Maka dari itu hasil pengukuran sulfur dioksida (SO2) yang dilakukan di 2 lokasi dan 8 titik penelitian tidak ditemukan di karenakan lokasi yang jauh dari aktivitas industri dan tidak adanya proses-proses alami yang terjadi.
\end{abstract}

\section{KESIMPULAN}

a. Konsentrasi Karbon Monoksida (CO) pada pagi dan sore hari dijalan A.P. Pettarani dan jalan Rapoccini Raya Kota Makassar, hasil tertinggi pada sore hari dijalan A.P. Pettarani (persimpangan jalan urip sumoharjo) sebesar $18.580 \mu \mathrm{g} / \mathrm{Nm} 3$, sedangkan hasil terendah pada sore hari dijalan Rapoccini Raya (persimpangan jalan pettarani) sebesar $5.239 \mu \mathrm{g} / \mathrm{Nm3}$. masih memenuhi syarat yang ditetapkan oleh Peraturan Gubernur Sulawesi Selatan Nomer 69 Tahun 2010 Tentang Baku Mutu Udara Dan Kriteria Kerusakan Lingkungan
Hidup, untuk Karbon Monoksida dengan standar $30.000 \mu \mathrm{g} / \mathrm{Nm} 3$.

b. Konsentrasi Sulfur Dioksida $\left(\mathrm{SO}_{2}\right)$ pada pagi dan sore hari dijalan A.P. Pettarani dan jalan Rapoccini Raya Kota Makassar, hasil yang didapatkan (Nihil), berarti SO2 nya masih memenuhi syarat yang ditetapkan oleh Peraturan Gubernur Sulawesi Selatan Nomer 69 Tahun 2010 Tentang Baku Mutu Udara Dan Kriteria Kerusakan Lingkungan Hidup, untuk Sulfur Dioksida dengan standar $900 \mu \mathrm{g} / \mathrm{Nm} 3$.

\section{SARAN}

a. Sebagai pemerintah sebaiknya melakukan pemantauan Konsentrasi Karbon Monoksida dan Sulfur Dioksida 3 bulan sekali sehingga dapat dilakukan upaya pencegahan dari dampak yang ditimbulkan.

b. Memberikan penyuluhan kepada masyarakat mengenai dampak yang ditimbulkan apabila menghirup karbon monoksida dan sulfur dioksida dalam jumlah yang berlebihan.

c. Untuk peneliti selanjutnya dalam pengukuran dapat memperhatikan kecepatan angin, suhu, kelembaban.

\section{DAFTAR PUSTAKA}

Amelia Dkk. 2014. Karbon Monoksida (CO). (online) http://airpollution201 weebly.com/dampak pencemaran udara karbon monoksida. diakses 9 Januari 2017.

Daniel Dwi Putra Dkk. 2006. Sifat Dan Karakteristik Sulfur Dioksida. (online) http://pengentau.weebly.com/2006/tentang-kami.html. diakses 25 Mei 2017.

Mukono H.J. 2008. Pencemaran Udara dan Gangguannya Terhadap Gangguan Saluran Pernapasan. Surabaya: Airlangga University Press.

Republik Indonesia. 2010. Peraturan gubernur Sulawesi Selatan No. 69 Tahun 2010 Tentang Baku Mutu dan Kriteria Kerusakan Lingkungan Hidup.

Sastrawijaya A. Tresna. 2009. Pencemaran Lingkungan. Jakarta: Rineka Cipta.

Wardhana Wisnu Arya. 2004. Dampak Pencemaran Lingkungan (Edisi Revisi). Yogyakarta: Andi Offset.

Zulfa, Aditya. 2011. Uji Adsorpsi Gas Karbon Monoksida (CO) Menggunakan Zeolit Alam Malang Dan Lampung. Skripsi. Universitas Indonesia. Depok. (online) https://digital 20284677-S1151-Aditya.Zulfa//kabon.monoksida//. diakses pada tanggal 20 Mei 2017. 